УДК 908

\author{
А. Л. Автушкова \\ Новосибирский государственный краеведческий музей \\ Красный пр., 23, Новосибирск, 630099, Россия \\ alinanet@ngs.ru

\section{НОВОСИБИРСКИЙ КРАЕВЕДЧЕСКИЙ МУЗЕЙ И ИССЛЕДОВАНИЕ АРХЕОЛОГИЧЕСКИХ ПАМЯТНИКОВ НА ТЕРРИТОРИИ НОВОСИБИРСКОЙ ОБЛАСТИ В 1920-1951 ГОДАХ}

Исследование памятников археологии в 20-40-х гг. XX в. на территории нынешней Новосибирской области было связано с двумя научными краеведческими организациями - Обществом изучения Сибири и ее производительных сил и Новониколаевским центральным краевым музеем. Последний не только выполнял роль собирателя коллекций с памятников, но и производил археологические разведки в тех местах, которые были определены программой хозяйственного освоения области. Систематизация и анализ письменных источников и вещественного материала, полученного при раскопках археологических объектов современной территории Новосибирской области в 1920-1940 гг., позволили наиболее полно охарактеризовать процесс становления и развития археологии в регионе и предположить, что именно в эти годы происходила закладка основ собственно новосибирской археологии.

Ключевые слова: Новосибирская область, Новониколаевский центральный краевой музей, Общество изучения Сибири, М. А. Кравков, Убинское озеро, Чертово городище, П. И. Кутафьев.

Период 1920-х - 1940-х гг. до сих пор остается «белым пятном» в истории археологии Новосибирской области. Тем не менее с первой половины XX в. накоплен значительный вещественный и документальный материал, «разрозненные» немногочисленные коллекции предметов хранятся в различных музеях, имеются папки с документами, до настоящего времени не изученные. Все данные необходимо осмыслить, структурировать, обобщить и представить как совокупность знаний об истории археологии изучаемого региона. Судя по архивным документам, закладка основ собственно археологии Новосибирской области началась тогда, когда под эгидой недавно образованного Общества изучения Сибири и ее производительных сил музеи и местные краеведческие общества организовывали комплексные экспедиции для обследования огромных тер- риторий, а весь найденный материал концентрировался в местном музее. Эти сведения подтверждаются в литературе, посвященной истории археологического изучения региона, где высказываются предположения о том, что период 1920-х - 1940-х гг. явился временем первичного стихийного накопления материала путем случайных сборов во время краеведческих экспедиций [Троицкая, 1979; Молодин, Савинов и др., 1980; Молодин и др., 1990; Троицкая и др., 1980; Троицкая, Бородовский, 1994; Троицкая, Сальникова, 1997].

Новониколаевский центральный краевой музей проявил инициативу еще до основания ОИС. Хранящиеся в музее коллекции являются доказательством активной самостоятельной работы, хотя роль музея как научно-исследовательской организации до сих пор не определена. Проведенная авто-

Автушкова А. Л. Новосибирский краеведческий музей и исследование археологических памятников на территории Новосибирской области в 1920-1951 годах // Вестн. НГУ. Серия: История, филология. 2017. Т. 16, № 3: Археология и этнография. С. 29-38.

ISSN 1818-7919

Вестник НГУ. Серия: История, ффилология. 2017. Том 16, № 3: Археология и этнография

(С) А. Л. Автушкова, 2017 
ром работа призвана обозначить место музея в истории археологических исследований территории Новосибирской области.

В статье дан обзор археологических исследований музея на основе не публиковавшихся ранее документов. Впервые собран весь материал, касающийся истории изучения археологических памятников на территории современной Новосибирской области. Введены в научный оборот малоизвестные документы из Государственного архива Новосибирской области, научного архива Института истории материальной культуры РАН, Государственного Эрмитажа. Источниковую базу составили полевые отчеты археологических экспедиций, снабженные фотографиями, планами, чертежами с места раскопок и рисунками основных находок. В тексте использованы открытые листы ученых, полученные на раскопки отдельных объектов либо целых территорий, акты приема и передачи артефактов из раскопанных памятников в музеи страны, личная переписка исследователей. Задействован вещественный материал с Чертова городища, сборы из окрестностей г. Новосибирска и Убинского озера из ГЭ и Новосибирского государственного краеведческого музея. Часть сопроводительных документов к коллекциям получена из фондов ГЭ и НГКМ. В процессе работы выявлены имена местных историков и краеведов, ранее обойденных вниманием исследователей. Таким образом, целью статьи является описание деятельности НГКМ в археологическом изучении Новосибирской области.

Для достижения этой цели были поставлены следующие задачи: собрать и сопоставить вещественные и письменные источники, касающиеся истории изучения археологических памятников на территории Новосибирской области, ввести полученный материал в научный оборот, определить роль отдельных ученых в данном процессе.

В апреле-мае 1920 г. в Новониколаевске открылись первые выставки музейной секции, созданной геологом В. А. Анзимировым в том же году [Гришанова, 2009]. Это событие можно считать датой рождения Новосибирского краеведческого музея. Одним из основных источников комплектования фондов и их дальнейшего пополнения стала организация полевых экспедиций.

В 1924 г. Новониколаевский центральный музей от имени заведующего М. А. Кравко- ва подал в Государственную академию истории материальной культуры ходатайство о выдаче ему Открытого листа на скорейшее исследование доисторической стоянки в долине р. Каменки. Было получено согласие на руководство раскопками С. И. Руденко, который в постскриптуме к прошению обосновал повышенное научное внимание к данному памятнику: «Городище на р. Каменке мною ... [не разборчиво], и, судя по собранной там коллекции, представляет большой интерес. Ходатайство Н. Николаевского музея поддерживаю. Ученый сотрудник Академии С. Руденко» ${ }^{1}$.

Еще в 1917 г. жители Новониколаевска обращали внимание на уничтожение имеющегося в черте города памятника археологии. В Государственном архиве Новосибирской области хранится уникальный документ обращение к Народному собранию о защите археологического объекта. В нем содержится просьба остановить разрушение Каменского городища новопоселенцами в разрастающейся части города - так называемой «Нахаловке» ${ }^{2}$. Поводом послужил тот факт, что «местность, занимаемая ею, заселена, и памятники старины при разделке огородов и усадеб погибают» ${ }^{3}$.

К сожалению, нами не выявлены материалы, однозначно свидетельствующие о проведении раскопок по полученному Открытому листу. Но какие-то работы на археологическом объекте были проведены, и коллекция, собранная в районе памятника, поступила в фонды новообразованного музея. Так, в отчете о работе музея за 1925 1926 гг. сказано: «...по археологии - подъемный материал из становищ и могильников окрестностей Новосибирска - 583 ед.». Сборы с городища на Каменке находятся в фондах ГЭ. С большей вероятностью можно говорить о том, что исследованный памятник - это Чертово городище, располагавшееся ранее по улице Кирова (ныне станция метро Октябрьская, здание Внешторгбанка) и не сохранившееся до наших дней.

В 1925 г. музей перешел в ведение ОИС, возникшего в Новониколаевске, и стал Музеем производительных сил Сибирского края [Сальникова, 2005. С. 48-66]. Музей получил статус краеведческого, одним из

\footnotetext{
${ }^{1}$ АИИМК РАН. Ф. 2. Д. 124. Л. 2.

${ }^{2}$ ГАНО. Ф. Д. 97. ОП. 1. Д. 244. Л. 8-9.

${ }^{3}$ АИИМК РАН. Ф. 2. Д. 124. Л. 1.
} 
направлений деятельности было изучение производительных сил Сибири, что позволяло расширить экспедиционную и научноисследовательскую работу. Еще одним положительным моментом в статусе центрального музея Сибири являлось быстрое пополнение фондов музея за счет материалов, добытых в разных экспедициях в Сибирском крае.

1920-е гг. стали «золотым веком» в истории Новосибирского краеведческого музея. Директором его в эти годы был Максимилиан Алексеевич Кравков, талантливый, разносторонне одаренный человек. По профессии геолог, он интересовался не только узкопрофессиональными проблемами, но и организовывал этнографические экспедиции, производил сбор археологического материала.

На одном из заседаний ОИС в 1926 г. М. А. Кравков сделал сообщение о результатах своей поездки на Убинское озеро в Барабинской лесостепи с целью добычи торфа. В стенографии протокола № 6 заседания ОИС приведен отчет об экспедиции: «Кравков (зав. Ново-Николаевским музеем), обрисовав географическое местонахождение Убинского озера, указывает, что на его берегу около д. ... находится 16 курганов. Два из них находились в опасности: в одном, оказавшемся на очень небольшой глубине, кости были вытащены волками или собаками. Само погребение покоилось на бересте, похожей на ... [не разборчиво], т. е. летнюю крышку чума у остяков и самоедов. Здесь, кроме скелетов, найдены кости лошади. Второй курган, находившийся на обрыве, разрушаемом очень сильно весенним подъемом воды ${ }^{4}$. Будущей весной его могло совершенно разрушить. При его раскопке найдены полный скелет с металлическим ножом под левой ладонью; а около головы сосуд» ${ }^{5}$. Датировка могильника не приводится. «Предложения к сообщению т. Кравкова: сделать доклад на собрании Общества, причем продемонстрировать весь добытый материал. Довести до сведения Глав-Науку о сделанных раскопках курганов и получить от нее разрешение для дальнейшей работы» ${ }^{6}$. Доклад был сделан на заседании Совета Общества 21 декабря 1926 г.

\footnotetext{
${ }^{4}$ Здесь и далее в цитируемых документах орфография и пунктуация сохранены.

${ }^{5}$ ГАНО. Ф. Р-217. ОП. 1. Д. 2. Л. 21.

${ }^{6}$ Там же. Л. 22.
}

Вещи, обнаруженные на памятнике, вероятно, попали в народный музей Новосибирска. В НГКМ хранится коллекция предметов, собранных на берегах Убинского озера до Великой Отечественной войны, а именно: бронзовая личина, наконечники железных копий, фрагменты керамики. Долгое время в музее хранились кости человеческого скелета, найденные в Убинском районе до войны ${ }^{7}$.

В 1926 г. председателем подсекции «Человек» ОИС Н. К. Ауэрбахом планировался выпуск сборника «Успехи археологии России за 10 лет (1917-1926 гг.)». В связи с этим сибирским музеям рассылались анкеты с просьбой заполнить графу о состоянии археологической коллекции в фондах. Самим Новосибирским краевым музеем на местах велась массовая просветительская работа среди населения с целью разъяснения людям ценности памятников культурного наследия, в частности археологических объектов. Людей просили при обнаружении памятников сообщать о них специалистам музея или органам власти. Музей руководствовался резолюциями ОИС о развитии массовости краеведческого движения. «Борьба за массовость краеведческого движения, - писала Е. Ф. Курочкина, - за его всенародный характер была в центре внимания... Общества изучения Сибири и ее производительных сил, почти на всех сессиях Совета ОИС делались доклады и принимались решения по этому вопросу» [1968].

Это дало результаты. С разных концов Новосибирской части Сибирского края от добровольных помощников стали поступать сведения о расположенных в округах памятниках. Имеется, например, такое: «Лебедева Галина Ипполитовна. Ст. Чулымская, Омская железная дорога. Учительница железнодорожной школы. Кости мамонта обнаружены около железнодорожной водокачки на реке Омь в 21 версте от ст. Кожурла. Ехать надо до ст. Кожурла ... [не разборчиво], машиниста не знает, имя Гавриил Алексеевич. Скелет человека 4 (два взрослых и два детских) обнаружены крестьянами ... [не разборчиво] объезде в р. Омь при работах по улучшению съезда. Живут около p. Омь, где есть деревня. Название деревни

\footnotetext{
${ }^{7}$ В настоящее время в фондах отсутствуют.
} 
никто не знает. Сообщение сделано Лебедевой в июне 1927. Записывал Ауэрбах» ${ }^{8}$.

После отставки от должности директора Музея производительных сил Сибирского края М. А. Кравкова в 1930 г. на нее был назначен П. И. Кутафьев - любитель древних вещей, археолог-самоучка. Биографы П. И. Кутафьева Я. Яковлев и Ю. Рассамахин ставят его в один ряд с виднейшими сибиреведами довоенной эпохи ${ }^{9}$.

24 июня 1930 г. Главнаука выдала П. И. Кутафьеву открытый лист на обследование археологического памятника Чертово городище. Отчет о проведенных раскопках не сохранился. Эта экспедиция, как и деятельность П. И. Кутафьева на посту директора Новосибирского областного краеведческого музея, остается до конца не изученной по причине отсутствия отчетов или полевых дневников. В мае 1933 г. П. И. Кутафьев был освобожден от должности директора «за политическую близорукость» и отправлен на работу заведующим Тымской производственно-охотничьей станцией в пос. Ваниль-Кыпак Нарымского округа, а позднее стал директором Колпашевского музея в Томской области. Из всего архива семьи Кутафьевых у дочери П. И. Кутафьева, Л. П. Харченко, сохранились два открытых листа, выданных П. И. Кутафьеву на раскопки Чертова городища и в Нарымском крае Новосибирской области, а также три фотографии с раскопок. В фондах НГКМ имеется коллекция предметов с памятника в Нарымском крае. Есть все основания полагать, что это сборы П. И. Кутафьева, с меньшей степенью вероятности - произведены иркутским археологом П. П. Хороших в 1930-е гг. [Троицкая и др., 1980. С. 10].

В статье П. П. Хороших «Неисследованные пещеры Салаира» [1949] упомянуты раскопки П. И. Кутафьевым пещеры Изылы. Там он ошибочно обозначен как А. И. Кутафьев. Однако, по заверениям Л. П. Харченко, ее отец после ссылки в Нарым ни в 1935 г., ни позднее, не приезжал в Новосибирск на раскопки. Тем более что участь его как сосланного «за политическую близорукость» была незавидна. Поэтому исследование пещеры проводил кто-то другой. В от-

\footnotetext{
${ }^{8}$ ГАНО. Ф. Р-217. Оп. 1. Д. 65. Л. 15.

${ }^{9}$ См.: Яковлев Я., Рассамахин Ю. У истоков Колпашевского краеведческого музея: Петр Иванович Кутафьев. URL: http://elib.tomsk.ru/purl/1-2564/ (дата обращения 20.08.2016).
}

четах музея нет сведений ни об одной проведенной в период с 1933 по 1936 г. археологической экспедиции, но в составе коллектива упоминался археолог ${ }^{10}$. Имя и фамилия этого человека не сохранились, он проработал всего год. В 1936 г. археологи в штате музея не значатся. Предположительно Изылы - результат раскопок именно этого безымянного археолога. Им был собран значительный материал, хранящийся в фондах НГКМ. Сведений о раскопках пещеры Изылы П. И. Кутафьевым пока не найдено, кроме названной статьи П. П. Хороших.

В 1939 г. на работу в музей был принят Ефим Дмитриевич Стрелов. До этого назначения он работал архивариусом в Якутском областном управлении, но 12 ноября 1928 г. был уволен без права приема в государственные и общественные учреждения. В 1933 г. он переехал в Новосибирск. С тех пор началась его трудовая деятельность на посту сотрудника музея. Он активно включился в работу. Летом 1939 г. Е. Д. Стрелов организовал отряд юных археологов из учащихся 10-х классов в составе 50 человек и разработал план разведки - «экскурсии» по р. Бердь. В задачи отряда входило обследование берегов реки от ее верховьев до впадения в Обь и проверка поступивших сведений о наличии по берегам археологических памятников. Экспедиция была снабжена необходимым для работы оборудованием. В результате обнаружено 10 памятников: 2 городища, 6 стоянок и 2 курганных могильника ${ }^{11}$. Весь добытый материал был передан в музей. Отчет об экспедиции отсутствует.

В 1941 г. в Облплан директором музея Косовым была подана докладная записка, в которой сообщалось о наличии в Новосибирской области большого числа археологических памятников, нуждающихся в скорейшем обследовании по причине их возможного разрушения. Он указал на некоторые объекты: «древнее городище в Бердске, неолитическая стоянка за Заельцовским бором, Чертово городище, несколько стоянок по берегам Нарыма и Томи и много других» ${ }^{12}$. Директор сетовал на печальное положение, в котором находился краеведческий музей: из-за недостатка средств он не мог проводить полномасштабные археоло-

\footnotetext{
${ }^{10}$ ГАНО. Ф. 1813. Оп. 1. Д. 2. Л. 68.

${ }^{11}$ Там же. Д. 3. Л. 1.

12 Там же. Д. 7. Л. 9.
} 
гические исследования. В связи с этим он просил отпустить 8000 руб. на организацию полевых работ в Новосибирской области летом 1941 г.

В докладе музея о летних полевых работах, которые он обязался произвести совместно с Областной детско-туристской станцией, Геолого-разведывательным и Гидрометуправлением, обкомом комсомола в 1941 г., в частности, говорилось: «В задачу археологических исследований входит: учет и описание разнообразных археологических памятников - городищ, курганов, могил, пещер, древних надписей на скалах и др. без права раскопок этих памятников» ${ }^{13}$. Кроме того, могли проводиться в редких случаях охранные раскопки. «Все собранные материалы исследовательских походов должны поступать в штаб похода, где они будут рассматриваться соответствующими специалистами, после чего будут переданы в соответствующие музеи области» ${ }^{14}$.

По итогам исследований школьникам предписано составлять карты (например, карта распространения археологических памятников). В конце 1941 г. участники экспедиции намеревались организовать выставку результатов летних походов.

Был составлен производственный план научно-исследовательских работ на археологических памятниках, куда входили обследование и раскопки городищ около Колывани, курганного могильника близ с. Атаманово, курганного могильника близ с. Тогучин, разведка Салаирских пещер, разведка группы курганов в Чистоозерном районе близ фермы № 2 Юдинского овцесовхоза ${ }^{15}$. Кроме этого, планировалось организовать несколько краткосрочных экспедиций по сбору археологических материалов, а также образовать 4 исторических кружка в районах и в городе для сбора археологических и исторических материалов. Предполагалось произвести учет и описание памятников революции, исторических, архитектурных и археологических ${ }^{16}$. Таким образом, мы видим, что музей имел достаточно обширные сведения о находящихся на территории области археологических памятниках. Для их исследования намечалась широкая программа мероприятий, связанных с непо-

\footnotetext{
${ }^{13}$ ГАНО. Ф. 1813. ОП. 1. Д. 7. Л. 5.

${ }^{14}$ Там же. Л. 6.

${ }^{15}$ ГАНО. Ф. 1813. Оп. 1. Д. 9. Л. 4-5.

${ }^{16}$ Там же.
}

средственным выездом на объекты, их осмотром и описанием, а при необходимости и аварийными раскопками с последующим составлением археологической карты области.

Однако в связи с началом Великой Отечественной войны 22 июня 1941 г. научноисследовательским отрядам приказано срочно вернуться на базу, а 25 июля 1941 г. был получен приказ «свернуть экспозицию, укупорить все музейные ценности, сдать их до конца войны на хранение в Дом науки и культуры ${ }^{17}$ и передать здание для военных надобностей» ${ }^{18}$

Приказ о передаче экспонатов на хранение в недостроенный Оперный театр оказал негативное влияние на сохранность археологического фонда. Часть экспонатов действительно была отдана по приказу, часть «разбрелась» по школам города и области. После окончания войны сотрудникам музея удалось разыскать и возвратить лишь часть экспонатов. Причем документация, сопровождавшая их, пропала. Сегодня в музейном археологическом фонде существует коллекция, именуемая «старые археологические поступления». Это как раз часть той коллекции, возвращенная музею после войны. Перед сотрудниками музея стоит проблема восстановления утраченных сведений об истории артефактов.

Конечно, с войной вся научно-исследовательская деятельность музея была прекращена. Но сотрудники не оставляли попыток продолжить работу, начатую до войны. Уже в плане музея на 1942 г. мы находим такой пункт: «Научно-исследовательская работа по историческому отделу - проведение предварительного обследования городища вблизи г. Колывани по имеющейся заявке местных старожилов на предмет производства археологических раскопок» ${ }^{19}$. В плане на 1944 г. по научно-исследовательской работе все еще стоит «предварительное обследование древнего городища у Колывани» ${ }^{20}$. Видимо, работа по изучению памятников так и не была выполнена в течение всего военного времени. Однако в плане наметились подвижки. Сотрудникам музея вменялось в обязанность «провести подготовку

17 Ныне Новосибирский государственный академический театр оперы и балета.

${ }^{18}$ ГАНО. Ф. 1813. ОП. 1. Д. 11. Л. 2.

${ }^{19}$ Там же. Д. 13. Л. 1-3.

${ }^{20}$ Там же. Д. 18. Л. 2. 
к организации в 1945 году исследовательского похода по области силами учащихся, прерванного в 1941 г. ввиду закрытия музея и туристической станции» ${ }^{21}$.

На 1946 г. было намечено «провести раскопки городища около г. Колывани или курганов в районе Атаманова - 3 квартал. Ответственный за выполнение - Е. Д. Стрелов» ${ }^{22}$. Но работа не была выполнена из-за нехватки средств.

И только в 1947 г. средства на организацию летних полевых работ выделены в размере 5000 руб. В 1949 г. разработана примерная «Программа - задание для краеведческих кружков и перечень памятников ... [не разборчиво] в г. Новосибирске за 1948 г.» ${ }^{23}$. В пункте «для археологии» предписывалось собрать сведения об археологических памятниках, провести внешний осмотр, описать, составить карту их размещения на территории района, колхоза и т. д. ${ }^{24}$ Далее краеведам, отправляющимся в поход, давались советы «что и где искать». В Комиссию по отделам «культурно-просветительного» учреждения при Совете Министров, лично заместителю директора комиссии т. Клабуновскому, отправлялся «перечень археологических памятников, расположенных на территории Новосибирской области:

1. 14 земляных курганов татаро-монгольского погребения, Аул Чека Кыштовского района Новосибирской обл.

2. 15 земляных курганов-могильников (ориентировано - татаро-монгольские погребения) ${ }^{25}$, при впадении р. Тартас в р. Омь от села Венгерово, Венгеровского р-на.

3. 3 земляных городища неизвестного периода около г. Колывани, Колыванского р-на.

4. Следы 1 стоянки первобытного человека; остатки костей мамонта и каменных орудий человека около г. Бердска.

5. Кости человека и орудия из железа, г. Тогучин (пещера в 15 км от г. Тогучин).

6. Стоянка человека неолита и бронзы, г. Новосибирск, южная часть парка им. Кирова.

7. Земляной вал. Следы бывшего Чауского острога-крепости, с. Чаус Колыванского р-на.

\footnotetext{
${ }^{21}$ ГАНО. Ф. 1813. Оп. 1. Д. 18. Л. 3.

${ }^{22}$ Там же. Д. 25. Л. 2.

${ }^{23}$ Там же. Д. 37. Л. 1-2.

${ }^{24}$ Там же. Д. 37. Л. 1-2.

${ }^{25}$ Так в рукописи.
}

8. Земляной вал. Следы бывшего Бердского острога-крепости, г. Бердск» ${ }^{26}$.

В рабочем плане музея 1949 г. стояла задача составления подробного вопросника по учету памятников истории, археологии и палеонтологии для отправки в районы области. Кроме этого, предполагалось составить археологическую карту по материалам, хранящимся в музее, и сборам музеев области, а также провести раскопки одного из курганов. Продолжалась работа по выявлению памятников археологии и палеонтологии. Ответственным за выполнение назначался краевед Б. С. Семенов ${ }^{27}$.

Б. С. Семенов - специалист-ботаник, выпускник Казанского университета, в 19181919 гг. работал на полуострове Таймыр, в районе Дудинки и Норильска [Денисов, 2009. С. 144], возглавлял Западно-Сибирский краевой музей в 1921-1922 гг., являлся секретарем Западно-Сибирского отдела Русского географического общества. Во время работы в музее совершил несколько экспедиций в качестве специалиста по биологии и лихенологии по Тарскому округу Омской области, притокам Томи, Алтаю и Саянам совместно с П. Л. Дравертом, С. Д. Лавровым и др. Результаты исследований были опубликованы им на страницах краеведческого журнала «Сибирская природа» [Ремизов, 1998. С. 29-30, 54-55; Секретов, Бугаева, 1998. С. 9]. В 1922 г. между председателем ЗСОРГО П. Л. Дравертом и Б. С. Семеновым произошел конфликт, в результате которого последний был обвинен в распродаже музейных ценностей. Суд признал Б. С. Семенова виновным и приговорил к трем годам лишения свободы и ограничению гражданских прав на тот же срок ${ }^{28}$. Позднее он работал на Алтае и в Новосибирске. Летом 1949 г. Б. С. Семенов проводил исследование неолитической стоянки у г. Бердска и курганного могильника Кротово-1 у с. Кротово в Сузунском районе, где им был раскопан один курган. Естественно, все материалы он передал в музей.

Директором НОКМ М. М. Зорким в 1949 г. были осмотрены несколько памятников во Вьюнском сельсовете Колыванского района. Археологические сборы музея 1949 г. послужили основой для разработки экскурсии

\footnotetext{
${ }^{26}$ ГАНО. Ф. 1813. Оп. 1. Д.42. Л. 6.

${ }^{27}$ Е. Д. Стрелов к тому моменту уже умер.

${ }^{28}$ Газета «Рабочий путь». Омск, 1925. № 16.
} 
«О древнем населении Новосибирской области» ${ }^{29}$. Фонды археологии увеличились на 251 единицу.

В отчете о деятельности музея за 1949 г. есть упоминание об отчетах о работах полевых отрядов летом 1933-1937, за 1948-1949 и другие годы. В настоящее время в фондах музея они отсутствуют, и где находятся, сказать пока невозможно. Их находка раскроет еще одну страницу в истории археологических исследований НОКМ.

С 1949 г. регулярно ведутся поиски археологических памятников области, ареал поисков расширяется. Летом 1950 г. планировалось провести краеведческий поход по маршруту Новосибирск - деревня Батурино - Вьюнский сельсовет Колыванского района в течение 20 дней. Б. С. Семеновым составлены проекты 5-, 15- и 25-дневных маршрутов для местных школ по Новосибирской области. Результатом поездки стало пополнение фонда археологии музея на 117 единиц. В 1950 г. вышла в свет брошюра для краеведов «По реке Уень», где, кроме прочего, упоминаются археологические памятники, обнаруженные по берегам реки в результате разведки 1949 г.: «В окрестностях Уеня имеются и исторические памятники. Во Вьюнской лесной даче, которая примыкает к обской пойме и ограждается от нее рядом маленьких болот-озер, известных под общим названием «Речка - Чучка», имеются следы жилищ древнего человека. Таких «городищ» восемь. Одно из них расположено в Кашламском бору на берегу озера. Городища никем не исследованы и открыты только в 1949 г. Местное население относит их к XII-XIII вв. Давным-давно здесь жила чудь какая-то, говорят старики. Изучение этих городищ, занесение на план, зарисовки их и фотографирование представляет большой интерес» ${ }^{30}$. По такому описанию сложно судить о наличии и состоянии археологических памятников в Колыванском районе.

В планах 1951 г. предписывалось организовать краеведческий поход «силами актива музея по обследованию и сбору материала с древних стоянок около деревень Луговой, Верх-Ирмень и Вьюны». Сотрудники музея собирались провести научную обработку материала, собранного с Бердской и Кро-

\footnotetext{
${ }^{29}$ ГАНО. Ф. 1813. Оп. 1. Д. 45. Л. 4-15.

${ }^{30}$ НГКМ. ОФ-20592/172.
}

товской стоянок. В отчете за 1951 г. составители жалуются на отсутствие «возможности производить собирательскую работу по археологии, т. к. [музей] не имеет археолога и открытого листа на раскопки, хотя каждый год музей вносит в список вновь открываемые месторасположения курганов, городищ, стоянок на территории Новосибирской области» ${ }^{31}$.

В 1952 г. в Новосибирске появился сотрудник ЛГАИМК М. П. Грязнов. Новосибирская экспедиция ЛГАИМК, возглавляемая им, в течение трех лет вела раскопки на территории будущего затопления Новосибирской ГЭС. М. П. Грязновым исследованы несколько замечательных памятников, среди них поселение ирменской культуры Ирмень-1, комплекс разновременных памятников Ордынское-1 и др. Между экспедицией М. П. Грязнова и НОКМ была налажена прочная связь. В Новосибирской экспедиции М. П. Грязнова принимал участие и сотрудник музея Б. С. Семенов. Благодаря этому в музей поступили материалы памятника Ирмень-1 в виде фрагментов керамических сосудов и одного целого сосуда, а также отчетов и фотографий с места раскопок.

Подводя итог, следует отметить, что за столь короткое время НОКМ сумел проделать колоссальную научно-исследовательскую работу в области изучения археологических памятников Обь-Иртышья, собрал сведения о многих объектах, сформировал значительную археологическую коллекцию, известную как «старые поступления». В результате был сделан шаг к созданию археологической карты региона и к развитию этой науки в Новосибирской области еще в довоенный период. Сотрудники музея регулярно организовывали экспедиции для поиска археологических памятников в различных частях Новосибирской области и комплексные экспедиции для исследования истории Сибири в рамках освоения природных и культурных ресурсов региона. «Старые поступления» являются одной из самых интересных и таинственных частей археологического фонда музея, потому что у нас нет информации о том, с какого памятника происходят эти вещи и, кроме нескольких случаев, кто является автором раскопок. После восстановления полной информации, введения в научный оборот и в образовательный

\footnotetext{
${ }^{31}$ ГАНО. Ф. 1813. Оп. 1. Д. 57. Л. 7.
} 
процесс данные предметы должны помочь ученым расширить имеющиеся знания об историческом прошлом данного региона Сибири.

\section{Список литературы}

Гришанова T. В. 90 лет со времени открытия Новосибирского краеведческого музея (1920) // Календарь знаменательных и памятных дат по Новосибирской области. Новосибирск, 2009. С. 97-101.

Денисов В. И. Хронология Таймыра: хронология исторических событий генезиса Таймыра и Норильского района. Норильск: АПЕКС, 2009. 224 с.

Курочкина Е. Ф. Из истории организации научно-исследовательской работы в Сибири (Общество по изучению Сибири и ее производительных сил) // Бахрушинские чтения. 1966 г.: Сб. науч. тр. / Отв. ред. А. П. Окладников. Новосибирск, 1968. Вып. 3: Сибирь в эпоху социализма. 194 с.

Молодин В. И., Савинов Д. Г., Елагин В. С., Соболев В. И. Бараба в тюркское время. Новосибирск: Наука, 1980. 176 с.

Молодин В. И., Соболев В. И., Соловьев А. И. Бараба в эпоху позднего средневековья. Новосибирск: Наука, 1990.

Ремизов А. В. Омское краеведение 1930 1960 гг. Очерк истории. Омск, 1998. Ч. 1. $179 \mathrm{c}$.

Сальникова И. В. Документальная летопись Новосибирского государственного краеведческого музея // Образовательная деятельность музея: Сб. ст. к 85-летию музея. Новосибирск, 2005. С. 48-66.
Секретов А. А., Бугаева Т.С. Б. С. Семенов // 175 лет Омской области (краеведы Омского Прииртышья). Омск, 1998. 29 с.

Троищкая T. Н. Кулайская культура в Новосибирском Приобье. Новосибирск: Наука, $1979.114 \mathrm{c}$.

Троицкая Т. Н., Бородовский А. П. Большереченская культура лесостепного Приобья. Новосибирск: Наука, 1994. 184 с.

Троицкая Т. Н., Молодин В. И., Соболев В. И. Археологическая карта Новосибирской области. Новосибирск: Наука, 1980. 183 c.

Троицкая Т. Н., Сальникова И. В. Участие Новосибирского областного краеведческого музея в исследованиях области // 60-летие Новосибирской области: Материалы науч.практ. конф. Новосибирского областного краеведческого музея. Новосибирск, 1997. С. 27-30.

Хороших П. П. Неисследованные пещеры Салаира // Природа. 1949. № 8. С. 52-53.

\section{Список источников}

АИИМК РАН. Ф. 2. Д. 124. 3 л.

ГАНО. Ф. Р-217. Оп. 1. Д. 2. 30 л.; Д. 65. 221 л.; Ф. 1813. Оп. 1. Д. 2. 73 л.; Д. 3.9 л.; Д. 7.10 л.; Д. 9.11 л.; Д. 11. 5 л.; Д. 13. 3 л.; Д. 18. 3 л.; Д. 25. 4 л.; Д. 37.8 л.; Д. 42.8 л.; Д. 45. 172 л.; Д. 57. 30 л.; Ф. Д. 97. Оп. 1. Д. 244. 110 л.

ГАУК НСО «НГКМ». ОФ-20592/172. 34 с.

Материал поступил в редколлегию 28.11.2016

\author{
A. L. Avtushkova \\ Novosibirsk State Region Museum \\ 23 Krasny Ave., Novosibirsk, 630099, Russian Federation \\ alinanet@ngs.ru
}

\title{
NOVOSIBIRSK LOCAL MUSEUM AND RESEARCH OF ARCHAEOLOGICAL OBJECTS IN THE TERRITORY OF THE NOVOSIBIRSK REGION IN 1920-1951
}

Purpose. Article is intended to describe the role and activities of the Novosibirsk local museum in archaeological investigation of Novosibirsk region. Also the purpose of article is disclosure of a role of certain staff of the museum in this process. To achieve this goal, the following objectives have been defined: collect and organize work and real material relating to archaeological research in the territory; introduce new material into scientific circulation of integrated research and local history of expeditions to study archaeological sites in present-day Novosibirsk region; describe the activ- 
ities of individual scientists, scientific organizations and societies in the field of archaeological research of the Novosibirsk region, and determine their role in this process. The scientific novelty: in the work for the first time assembled and summarized all the material for the study of archaeological objects of modern Novosibirsk area. Introduced into scientific circulation until then little-known documents from the State archive of the Novosibirsk region and from the Department of Archaeology of Eastern Europe and Siberia of the State Hermitage, as well as the unknown archaeological collections of such museums in the country, as the State Hermitage (Chertovo settlement gathered on instructions from S. Rudenko Museum Novonikolaevsk of in 1924), the Novosibirsk Museum (materials of Berdsk settlements, which was investigated E. Strelov, 1939, barrow near the village of Krotovo, which was investigated by B. Semenov, materials in area of Novosibirsk from local campaigns by regional Museum, the cave Izyly, the artefacts, which was collected on the coast of Ubinskoe Lake in the pre-war period). During the work the names of local historians and scientists who have been studying the territory, but their role in this process either was not awarded the attention of the scientific world, or has been reduced.

Results. The author has used before unpublished archival sources and artifacts received from the State archive of the Novosibirsk region and Novosibirsk State Region Museum. The investigation found that the Museum staff regularly take separate expeditions to search for archaeological sites in parts of Novosibirsk region. Also periodically organized complex expedition for at exploring the history of Siberia with economic management of natural and cultural resources of the region. Research showed that since the basis Novosibirsk Museum could make huge work on research in the investigation of archaeological sites of the area between rivers $\mathrm{Ob}$ and Irtysh, as well as a large archaeological collection formed, known in this moment as «the old collection». Before Great Patriotic War was made a step towards the creation of archaeological maps of the region and by the early archaeology of the Novosibirsk region.

Conclusion. «The old collection» is one of the most interesting and mysterious parts of the collection of archaeology, because we do not have any information about what the sites to occur these things, except in rare cases, who is the author of the excavations. These collections, after restoring the full information about them and introducing them to scientists in order to increase their accessibility to the educational process, should help scientists broaden existing knowledge about the historical past of Siberia.

Keywords: Novosibirsk region, Novonikolaevskii Central Regional Museum, Society for the Study of Siberia, M. A. Kravkov, Ubinskoe Lake, Devil's mound, P. I. Kutafiev.

\section{References}

Denisov V. I. Khronologiya Taimyra: khronologiya istoricheskikh sobytii genezisa Taimyra $i$ Noril'skogo raiona [The chronology of Taimir: the chronology of historical events of genesis of Taimir and Norilsk area]. Norilsk, APEKS Publ., 2009, 224 p. (in Russ.)

Grishanova T. V. 90 let so vremeni otkrytiya Novosibirskogo kraevedcheskogo muzeya (1920) [90 years since opening of Novosibirsk region museum]. Kalendar' znamenatelnykh i pamiatnykh dat po Novosibirskoi oblasti [The calendar of famous dates of Novosibirsk region]. Novosibirsk, GANO Publ., 2009, p. 97-101. (in Russ.)

Khoroshikh P. P. Neissledovannye peshchery Salaira [Unexplored caves of Salair]. Priroda [Nature], 1949, no. 8, p. 52-53. (in Russ.)

Kurochkina E. F. Iz istorii organizatsii nauchno-issledovatel'skoi raboty v Sibiri (Obshchestvo po izucheniyu Sibiri i ee proizvoditel'nykh sil) [From history of organization of the scientific investigations in Siberia (The Society of study of Siberia and his productive opportunity)]. Bakhrushinskie chteniya. 1966 g.: sbornik nauchnykh trudov. Vyp. 3 :Sibir'v epokhu sotsializma / Otv. red. A. P. Okladnikov [The readings of Bakhrushin. 1966: The collection of scientific researches. 3 edition: Siberia in socialism]. Novosibirsk, NSU Publ., 1968, 194 p. (in Russ.)

Molodin V. I., Savinov D. G., Elagin V. S., Sobolev V. I. Baraba v tyurkskoe vremya [Baraba in Turkic era]. Novosibirsk, Nauka, 1980, 176 p. (in Russ.)

Molodin V. I., Sobolev V. I., Solov'ev A. I. Baraba v epokhu pozdnego srednevekov'ya [Baraba in later Middle Ages]. Novosibirsk, Nauka, 1990, 262 p. (in Russ.) 
Remizov A. V. Omskoe kraevedenie 1930-1960 gg. Ocherk istorii [The science of region in Omsk in 1930-1960. The sketch of history]. Omsk, OmGU Publ., 1998, part 1, 179 p. (in Russ.)

Sal'nikova I. V. Dokumental'naya letopis' Novosibirskogo gosudarstvennogo kraevedcheskogo muzeya [The chronicle of Novosibirsk State Region museum]. Obrazovatel'naya deyatelnost' muzeya. Sb. statei $k$ 85-letiyu muzeya [The educational activity of museum. Collection of articles to $85^{\text {th }}$ anniversary of museum]. Novosibirsk, NGKM Publ., 2005, p. 48-66. (in Russ.)

Sekretov A. A., Bugaeva T. S. B. S. Semenov [B. S. Semenov]. 175 let Omskoi oblasti (Kraevedy Omskogo Priirtysh'ya) [175 years of Omsk region (The local historican of Omsk region)]. Omsk, Administratsiya Omskoi oblasti Publ., 1998, 29 p. (in Russ.)

Troitskaya T. N. Kulaiskaya kul'tura v Novosibirskom Priob'e [The Kulayskaya culture in Novosibirsk Ob area]. Novosibirsk, Nauka, 1979, 114 p. (in Russ.)

Troitskaya T. N., Borodovskii A. P. Bol'sherechenskaya kul'tura lesostepnogo Priob'ya [The Bolsheretchenskya culture in Ob forest-steppe area]. Novosibirsk, Nauka, 1994, 184 p. (in Russ.)

Troitskaya T. N., Molodin V. I., Sobolev V. I. Arkheologicheskaya karta Novosibirskoi oblasti [The archaeological map of Novosibirsk region]. Novosibirsk, Nauka, 1980, 183 p. (in Russ.)

Troitskaya T. N., Sal'nikova I. V. Uchastie Novosibirskogo oblastnogo kraevedcheskogo muzeya $\mathrm{v}$ issledovaniyakh oblasti [The participation of Novosibirsk Region museum in region researches]. 60-letie Novosibirskoi oblasti: materialy nauchno-prakticheskoi konferentsii Novosibirskogo oblastnogo kraevedcheskogo muzeya 17-20 noyabrya $1997 \mathrm{~g} .\left[60^{\text {th }}\right.$ anniversary of Novosibirsk Region: the materials of sciencific-practic conference of Novosibirsk Region museum]. Novosibirsk, NOKM Publ., 1997, p. 27-30. (in Russ.)

\section{List of sources}

Arkhiv Instituta istorii material'noi kul'tury RAN (AIIMK RAN). [Archive of the Institute of History of the material culture (AIHMC)]. F. 2. D. 124. 3 p. (in Russ.)

Gosudarstvennyi arkhiv Novosibirskoi oblasti (GANO) [State Archive of Novosibirsk Region (SANR)]. F. R-217. Op. 1. D. 2. 30 p.; D. 65. 221 p.; D. 145. 65 p.; F. 1813. Op. 1. D. 2. 573 p.; D. 3.9 p.; D. 7. 10 p.; (in Russ.)

Gosudarstvennyi arkhiv Novosibirskoi oblasti (GANO) [State Archive of Novosibirsk Region (SANR)]. F. 1813. Op. 1. D. 9.11 p.; D. 11.5 p.; D. 13.3 p.; D. 18.3 p.; D. 25.4 p.; D. 37.8 p.; D. 42.8 p.; D. 45.172 p.; D. 57.30 p.; F. D. 97. Op. 1. D. 244. 110 p. (in Russ.)

Gossudarstvennyi arkhiv uchrezdeniya kul'tury Novosibirskoi oblasti «Novosibirskii gosudarstvennyi kraevedcheskii muzei» (GAUK NSO NGKM). [State Archive of the Novosibirsk region of culture «Novosibirsk State Museum of Local History» (NSMLH)]. OF-20592/172. 34 p. (in Russ.) 